\title{
On Strategy for the Promotion of Health Qigong In Benin $\mathrm{Wu} \mathrm{Xu}^{1}$, Liang $\mathrm{Xu}^{2^{*}}$
}

${ }^{1}$ School of Physical Education, Neijiang Normal University, Neijiang Sichuan, 641112, China

${ }^{2}$ School of Foreign Languages, Neijiang Normal University, Neijiang Sichuan, 641112 ${ }^{*}$ Corresponding author

Keywords: Health Qigong, Benin,Promotion

Abstract. As an important part of Chinese culture and Chinese specific regime, Health Qigong has now been promoted vigorously in Benin. As a former coach of Health Qigong in Benin, the author has done research on the popularization and promotion of Health Qigong based on its current situation, so as to stimulate the full development of Health Qigong there.

\section{Introduction}

Health Qigong, as a specific and comprehensive combination of traditional Chinese culture, regimen, respiratory regulation, extensibility of meridians and collaterals, Yin and Yang, physique training, psychological adjustment and small doses, unrestricted by place of exercise, is the $62^{\text {nd }}$ athletic activity authorized by the Chinese State General Administration of Sport and is propitious to the weather and current conditions in Benin. It has a heavy cultural foundation and focuses on the unity of body and soul, self-cultivation, harmonious coexistence of human and nature. Practitioners can also know more about China and Chinese culture through practicing it.

\section{Regimens and Health Qigong in Benin}

Benin, a southwestern country, located in the equatorial region, has tropical weather with year-round sunshine. Under such weather condition, the main regimens are soccer, basketball, jogging and aerobics with large amount of physical exertion, colliquative sweat and loss of nutrition, which are less healthy to people there. Meanwhile, the demands of those sports for the facilities, stadiums and gymnasiums are also big problems for the people and government in Benin.

The Chinese Cultural Center is the main institute providing both long-term and short-term Health Qigong courses. Each year, a professional coach will teach Health Qigong and give instruction and lectures there sponsored by Chinese State General Administration of Sport.

According to the status of Chinese Cultural Center in 2014, the number of registered members has gradually exceeded 200 since the first Health Qigong lecture held in 2010, with $90 \%$ local citizens of various career, such as public servants, 
lawyers, teachers, merchants, journalists, workers, peasants and students, etc. and $10 \%$ foreigners, such as French, Indians, Germans, Brazilians, Lebanese, etc. .

\section{Bottleneck for Promotion of Health Qigong in Benin}

Abstract Theories. The theory of Health Qigong derives from the Chinese traditional philosophy and culture, absorbed the essence of the thought of Confucianism, Buddhism, Taoism, Chinese Medicine, etc., which is more or less abstract to local practitioners. The explanation and Interpretation of Tao, Yin and Yang, Eight Diagrams, Meridians and Acupoints and such ideas of movement and motion as "there is Yang in Yin, and Yin in Yang; Motion in still, Still in Motion" must be a big problem for the practitioners and amateurs. There should be some common speech and explanations for its popularization. What's more, there indeed are some related religious terms and movements in Health Qigong that some local religious worshipper may not accept, although those terms and movements are only borrowed to have a macroscopic image for the common Chinese easy to understand and do not have any real religious meaning. Then how to avoid the misunderstanding and the potential discrimination and how to interpret in the correct and appropriate ways should be taken seriously by the related organizations, creators, researchers and coaches.

Shortage of Teaching Faculty. At present, the main faculty in Benin in charge of Health Qigong promotion are the coaches sent by the Chinese State General Administration of Sport, introducing Health Qigong exercises and regimen by the ways of delegation visit and short-term teaching and training course for free, which has made an achievement on the increase of the practitioners and primary instructors in number. However, this is temporarily a fabian policy that, to control the cost and expenses, the delegations and coaches can not stay there longer and the effect may be less better and restricted to a limited time period, when the local practitioners meet any problems and need instructions. Meanwhile, there is also a shortage of teachers who can teach and communicate freely by the local language. The shortage of faculty becomes a bottleneck for the promotion of Health Qigong in Benin.

Cultural Difference.The theoretical foundation of Health Qigong is Chinese traditional culture, which has attachment to the ancient philosophical schools, include the self-cultivation of Confucianism, surpass of Taoism and Buddhism, the disease prevention of Chinese Medicine, etc., namely, the specific way of thought, code of conduct, aesthetic views, attitude of Chinese has been reflected in it. Comparing to the western way of appreciating the stimulation, rivalry, adventure of sports, Health Qigong has reflected the Chinese traditional thought and sports of artistry, fair play, harmony, morality, skillful exercises and high morality. 


\section{Strategy for Sustainable Promotion of Health Qigong in Benin}

Localization of Health Qigong.The localization of Health Qigong refers to the localization of Teachers, language, teaching approaches, teaching material and contents.

The restriction to the promotion of Health Qigong is the quality and quantity of teaching faculty. It is quite necessary to build a local high-qualified teaching faculty, such as providing scholarships for the short-term and long-term training and academic education of the local excellent instructors to study in Chinese athletic education schools. It is also possible to build the training center in different areas of the nation for the local instructors, organizing lectures and providing courses given by the local teachers and explained by local languages or dialects.

Language is the carrier of culture. The localization of language does not only refers to the teaching language, but the interpretation of exercises, theories, terminology, ideas of regimen by dialect or common speech, which are popular and easy to understand.

The localization of teaching approaches demands that the related organizations should organize the local teaching faculty to gradually develop the appropriate teaching approaches for local teaching activities so as to realize the transformation of the practitioners from similarity in from to similarity in spirit, combining exercise with life, exercise with prevention of disease, exercise with mentality to achieve the state of unity of heaven and mankind.

The localization of teaching material demands the development of new textbooks, wall maps, picture albums, videos, guidance information, courses, CDs and e-books through new medias and propaganda ways, such as Internet, APP, Radio broadcasting, movies, etc. so that the practitioners can have an intuitionistic process of cognition, recognition, experience and practice.

The exercises of Health Qigong are based on Chinese traditional culture, combining the essences of Confucianism, Buddhism, Taoism, etc. The promotion of Health Qigong in Benin should be suitable to the national consciousness and religious habits, namely, the localization of content demands that the editors, creators and initiators should attach importance to respect the national consciousness and local religious habits, add or subtract and minimize properly the contents and movements about different religions, taboos, national consciousness and ideological divisions, try to synthesize the local customs and habits and develop brand new exercises suitable to the local situations and practitioners.

Sustainable Promotion and Introduction. Based on the radiation effect of Health Qigong, we may have a bottom-up promotion, that is to base on those areas that the practitioners are in big number and activities have been well organized, then 
deliver to other areas. It can also start from the local schools, gradually become one of the content of the Chinese culture lesson or PE lesson, then promote in people's daily life, at last, to be accepted by the government in charge of health and physical education. The second way is a top-down promotion. Health Qigong, a regimen, has been accepted by some officials and people of upper class since it was first introduced in Benin, because its unique way of keeping healthy. The Benin Ministry of Culture, Chinese Cultural Center and Confucius Institute have provide the legal and formal guarantee for the promotion of Health Qigong, and the local elite class, functionaries and Chinese entrepreneurs have become the economic, political and cultural foundation.

The promotion of Health Qigong can not live without its industrialization. The local organizations can provide the paid training courses to introduce the Chinese theory and philosophy of regimen, organize regional, states, international competitions and communications, promoting practice, making friends, spreading regimen by competition, develop and produce apparatus, clothing, stationery, learning CD, software, APP, movies relating to Health Qigong, organize certification test and promotion test for the local instructors, coaches and judges, and introduce Health Qigong by the famous Kung Fu stars.

\section{Conclusion}

Lacking in hospitals and medicine, the Chinese unique regimen Health Qigong will surely be embraced in Benin and become more and more popular among the people there.

\section{Acknowledgments}

The study was sponsored by Sichuan Health Qigong Research Key Project, 2014, No. SCQG 2014A004 and Neijiang Normal University Research Project, 2012, No.

12NJS17, named The Current Situation and Promotion of Health Qigong.

\section{References}

[1]Qiu Pixiang. Chinese Traditional Regimen. Beijing: People's Physical Culture Press, 2006.

[2] Xu Wu. Developing Trend and Promotion Strategy of Health Qigong. Journal of Neijiang Normal University,2015(2):97-100.

[3]Xu Wu. Application of Tong and Huo in Health Qigong. Journal of Health Qigong, 2011(5): 11-13.

[4]Yu Dinghai. On Promotion Strategy of New Exercises of Health Qigong. Journal of Wuhan Institute of Physical Education,2009(1): 65-73. 